\title{
Urocortin 2 treatment is protective in excitotoxic retinal degeneration
}

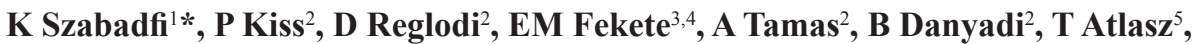 \\ R Gabriel ${ }^{1}$ \\ ${ }^{1}$ Department of Experimental Zoology and Neurobiology, Faculty of Sciences, University of Pécs, Pécs, Hungary \\ ${ }^{2}$ Department of Anatomy, PTE-MTA “Lendület” PACAP Research Team \\ ${ }^{3}$ The Scripps Research Institute, La Jolla, CA, USA \\ ${ }^{4}$ Department of Psychiatry, University of Wisconsin-Madison, Madison, WI, USA \\ ${ }^{5}$ Department of Sportbiology, University of Pécs, Pécs, Hungary
}

Received: April 2, 2013

Accepted after revision: May 25, 2013

\begin{abstract}
Urocortin 2 (Ucn 2) is a corticotrop releasing factor paralog peptide with many physiological functions and it has widespread distribution. There are some data on the cytoprotective effects of Ucn 2, but less is known about its neuro- and retinoprotective actions. We have previously shown that Ucn 2 is protective in ischemia-induced retinal degeneration. The aim of the present study was to examine the protective potential of Ucn 2 in monosodiumglutamate (MSG)-induced retinal degeneration by routine histology and to investigate cell-type specific effects by immunohistochemistry. Rat pups received MSG applied on postnatal days 1, 5 and 9 and Ucn 2 was injected intravitreally into one eye. Retinas were processed for histology and immunocytochemistry after 3 weeks. Immunolabeling was determined for glial fibrillary acidic protein, vesicular glutamate transporter 1, protein kinase $\mathrm{C} \alpha$, calbindin, parvalbumin and calretinin.

Retinal tissue from animals treated with MSG showed severe degeneration compared to normal retinas, but intravitreal Ucn 2 treatment resulted in a retained retinal structure both at histological and neurochemical levels: distinct inner retinal layers and rescued inner retinal cells (different types of amacrine and rod bipolar cells) could be observed. These findings support the neuroprotective function of Uen 2 in MSG-induced retinal degeneration.
\end{abstract}

Keywords: Ucn 2, MSG-excitoxicity, retinal degeneration, retina protection, morphology, immunohistochemistry

Since the isolation of corticotrophin-releasing factor (CRF), three mammalian CRF-like paralogs have been identified. The name, urocortins (Ucn 1, Ucn 2, Ucn 3), has been chosen due to the predicted predominant affinity of these peptides for the CRF2-receptor (CRF2-R). Ucn 1 and CRF resemble one another the most and they also bind to CRF1-receptors. Ucn 2 and Ucn 3 have similar structures and both peptides act as a preferential or selective CRF2-R agonists, leading to their designation as the selective CRF2-R agonists. High levels of Ucn 2 and its receptor have been observed in the heart, lung, muscle, stomach, blood cells, skin, placenta and hypothalamus, pituitary and adrenal medulla (14). Not surprisingly, urocortins have been proposed to participate in many physiological functions, including effects in the nervous system. Regarding neuroprotective functions, Ucn 1 has been shown to protect

Corresponding author: Krisztina Szabadfi, $\mathrm{PhD}$

*Winner of the Young Investigators Award, Hungarian Physiological Society, 2011

Department of Experimental Zoology and Neurobiology, Faculty of Sciences, University of Pécs

Ifjúság útja 6, H-7624 Pécs, Hungary

Phone: +36/72/503-600/24613; Fax: +36/72/501-517; E-mail: kriszta.szabadfi@gmail.com 
hippocampal neurons, cerebellar granule cells and to be protective in a model of Parkinson's disease $(9,21,22)$. Less is known about the protective functions of urocortins in the retina, where the CRF family peptides and their receptors have also been shown in different layers. CRF1-R $(27,35-40)$ and CRF2-R mRNA $(10,11)$ are also expressed in the retina and CRFlike immunoreactivity is abundant in GABAergic amacrine and horizontal retinal cells.

The mammalian retina, as a part of nervous system, is an excellent structure to study the effects of different neuropeptides. Glutamate is the main transmitter of the mammalian retina, but pathological increase of glutamate levels plays a key role in triggering neuronal damage in several retinal diseases $(28,33)$. Several human pathological conditions such as ischemia and some types of glaucoma can be mimicked by experimentally elevating the extracellular glutamate concentration or applying its analogues $(19,25,26,33)$. One such agent is monosodium glutamate (MSG) the application of which leads to the destruction of the entire inner retina $(8,18)$. We have previously described a model for excitotoxic retinal degeneration elicited with high amount of MSG, administered in repetitive and systemic ways: three times (postnatal days $1,5,9$ ) by subcutaneous injection (32).

Several agents and conditions have been shown to alleviate degenerative changes caused by elevated glutamate levels in the retina, such as NMDA-antagonists $(28,29)$, pituitary adenylate cyclase activating polypeptide (PACAP) $(6,7,32)$, diazoxide (3) and environmental enrichment (31). We have previously described that Ucn 2 has protective effects in ischemic retinal degeneration caused by bilateral common carotid artery occlusion (30). The aim of the present study was to investigate whether Ucn 2 applied simultaneously with MSG can reduce the damage of retinal structure and different retinal cells.

\section{Materials and Methods}

Newborn Wistar rats were housed under light/dark cycles of 12:12 h. Animal housing, care, and application of experimental procedures were in accordance with institutional guidelines under approved protocols (BA02/2000-24/2011; University of Pécs). They were injected s.c. with physiological saline $(n=8)$ or $2 \mathrm{mg} / \mathrm{g}$ body weight MSG $(n=16)$ on postnatal days (PD) $1,5$, and 9 . Ucn 2 ( $2 \mathrm{nmol})$ in $3 \mu \mathrm{l}$ phosphate buffered with saline (PBS) solution was injected into the right vitreous body after each MSG injection. The left eyes received the same volumes of vehicle (PBS) and served as normal eyes. On PD21, animals were killed with an overdose of anesthetic. Eyes were immediately dissected in ice-cold PBS and fixed in 4\% paraformaldehyde solution and retinas were processed for histological analysis as previously described $(1,32)$. Briefly, resin embedded retinal sections $(2 \mu \mathrm{m})$ were stained with toluidine blue. Samples for morphometric measurements derived from at least six tissue blocks prepared from at least three animals. Central retinal areas within 1 and $2 \mathrm{~mm}$ from the optic disc were used for measurements $(n=2-5$ measurements from one tissue block). We measured: (i) cross-section of the retina from the outer limiting membrane to the inner limiting membrane (OLM-ILM); (ii) the width of the outer and inner nuclear and plexiform layers (ONL, OPL, INL, IPL); and (iii) the number of cells/100 $\mu \mathrm{m}$ section length in the ganglion cell layer (GCL). Results are presented as mean \pm SEM. Statistical comparisons were made using one-way ANOVA test followed by Tukey-B post hoc analysis (GraphPadPrism5).

For immunohistochemistry, after the fixation the tissues were washed in PBS and cryoprotected in $10 \%$ sucrose for 1 hour, $20 \%$ sucrose in PBS overnight at $4{ }^{\circ} \mathrm{C}$. For cryostat sectioning, retinas were embedded in tissue-freezing medium (Tissue-Tek, OCT Compound), 
cut in a cryostat (Leica, Germany) at $10 \mu \mathrm{m}$ radially. Sections were mounted on chromealum-gelatincoated subbed slides and stored at $-20{ }^{\circ} \mathrm{C}$ until use. Retinal sections underwent immunohistochemical procedure as we previously described (2). Briefly, sections were incubated with the primary monoclonal or polyclonal antibody for overnight at room temperature. We used the following antibodies: anti-glial fibrillary acidic protein (GFAP; rabbit; 1:500; Sigma), anti-vesicular glutamate transporter 1 (VGLUT1; rabbit; 1:500; Sigma), anti-protein kinase $\mathrm{C} \alpha$ (PKC $\alpha$; mouse; 1:200; Chemicon), anti-calbindin (1:1000; mouse; Sigma), anti-parvalbumin (1:1000; mouse; Sigma) and anti-calretinin (1:1000; rabbit; Chemicon). After several washes in PBS, sections were incubated for $2 \mathrm{~h}$ in dark with the corresponding secondary antibodies (Alexa Fluor 488 and 568, Invitrogen). Sections were then washed in PBS and were coverslipped using Fluoromount-G (Southern Biotech). Digital photographs were taken with a Nikon Eclipse 80i microscope equipped with a cooled CCD camera. Images were taken with the Spot Basic software package. Photographs were further processed with the Adobe Photoshop 7.0 program. Images were adjusted for contrast only, aligned, arranged and labeled using the functions of the above program. Images were evaluated by an examiner blinded to the experimental treatment.

\section{Results}

In saline-treated normal preparations, all the layers characteristic for the mammalian retina were well visible (Fig. 1A). Ucn 2 treatments alone had no effect on normal control retinas (data and picture not shown). As we have previously described $(2,4,6,7,32)$, retinal tissue from animals treated with MSG showed severe degeneration compared to normal retinas. The IPL was markedly shrunk and the INL and GCL were intermingled (Fig. 1B). As a consequence, the total thickness of the retina was significantly reduced (Fig. 1D). Intravitreal Ucn 2 treatment resulted in a more retained retinal structure (Fig. 1C). The IPL remained visible and the INL and GCL were clearly separated (Figs. 1C, D). The number of cells in the GCL was significantly less than that of the control retinas. However, Ucn 2 administration following MSG treatment did not ameliorate the MSG-induced cell loss in GCL (Fig. 1E).
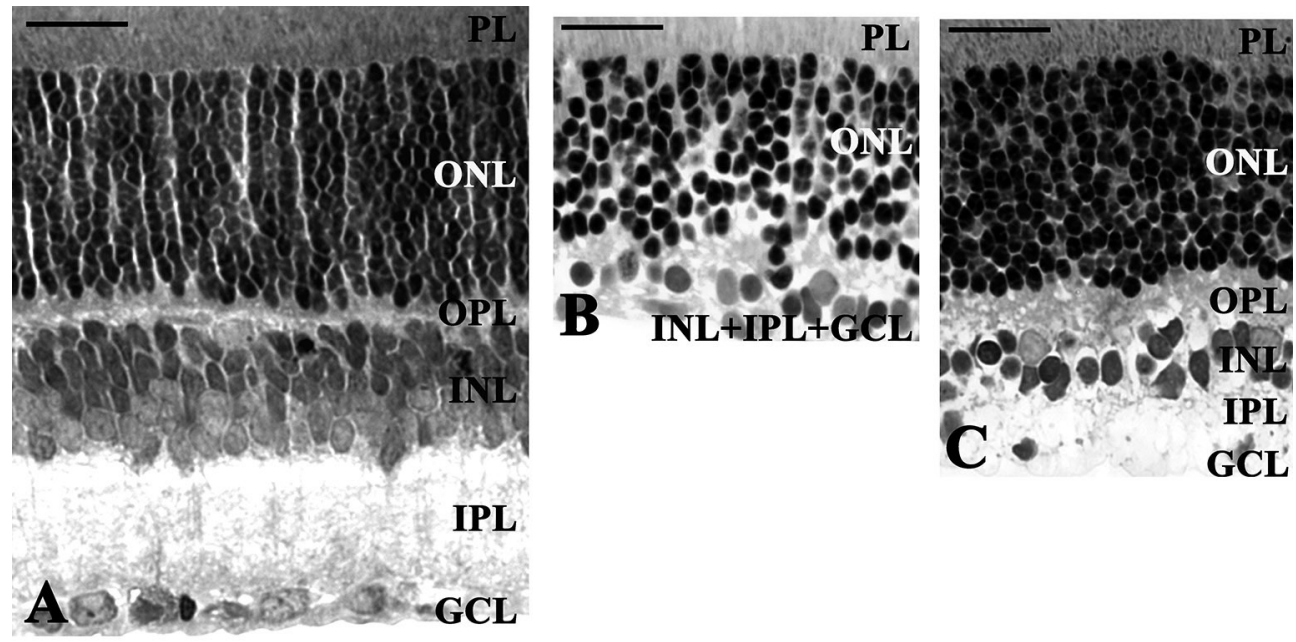

IPL 


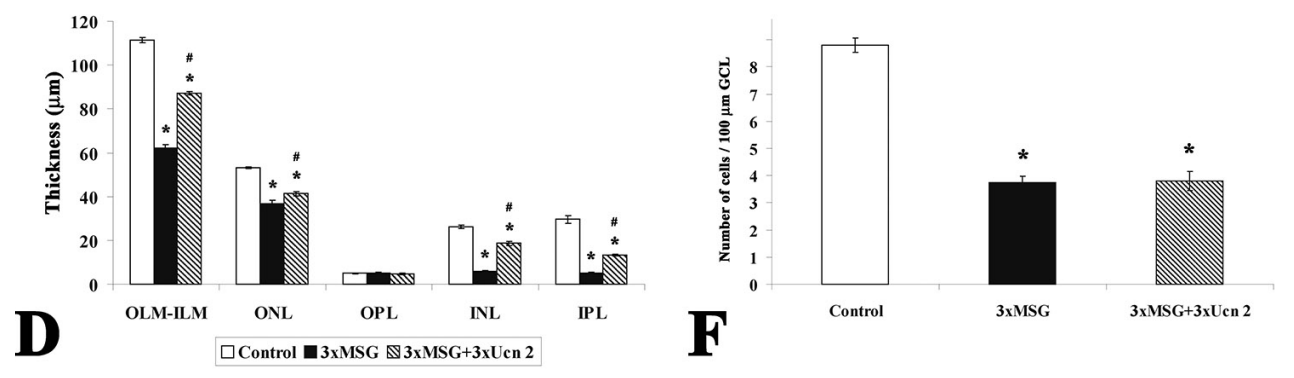

Fig. 1. Microphotographs of representative retinas from control (A), MSG- (B) and MSG+Ucn 2-treated retinas (C). Statistical comparison of the thickness of the whole retina and the retinal layers (D) and also the number of cells/100 $\mu \mathrm{m}$ ganglion cell layer (GCL) length (E).

${ }^{*} p<0.05$ compared to control retinas; $\# p<0.05$ compared to MSG-treated retinas.

Abbreviations: PL - photoreceptor layer; ONL - outer nuclear layer; OPL - outer plexiform layer; INL - inner nuclear layer; IPL - inner plexiform layer; GCL - ganglion cell layer. Scale bar: $20 \mu \mathrm{m}$

Glial fibrillary acidic protein (GFAP) is a metabolic stress marker $(12,20)$ expressed in the endfeet of retinal Muller glial cells in control condition (Fig. 2A). The MSG-induced elevation of GFAP expression could be detected in the whole glial cell. Massively upregulated immunopositivity was found throughout the cell from the OLM to the ILM (Fig. 2B). In Ucn 2-treated retinas the GFAP levels were reduced (Fig. 2C).

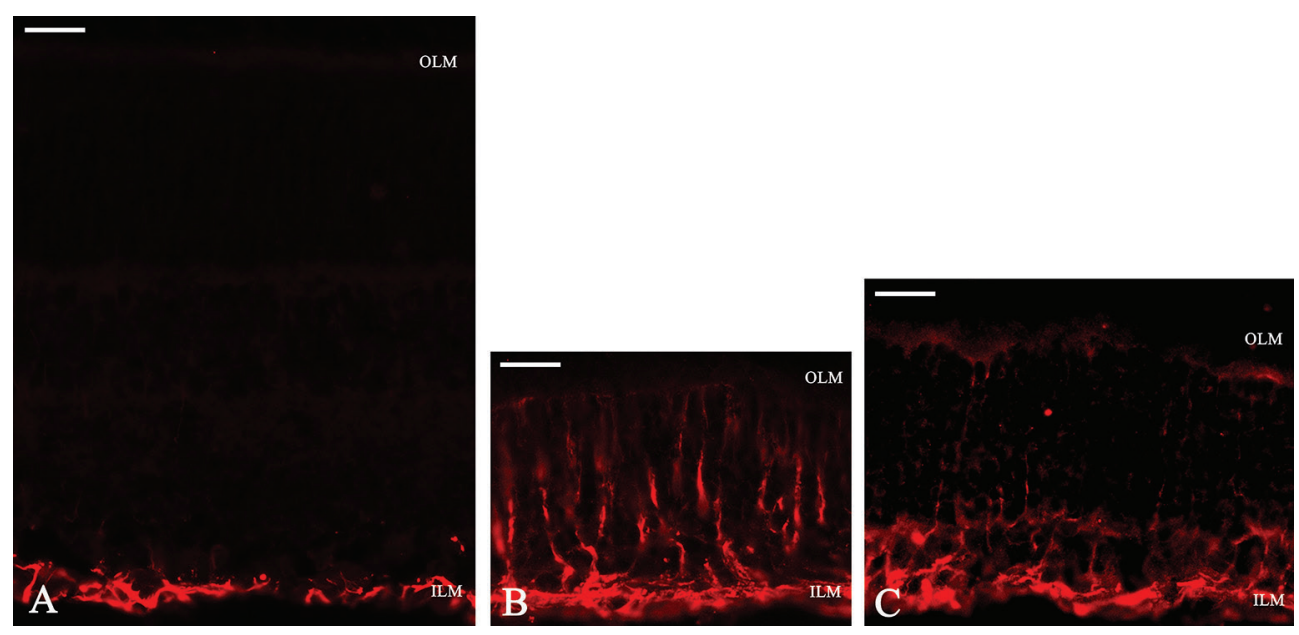

Fig. 2. GFAP-immunoreactivity in the rat retina.

In control retinas the Muller glial cells showed weak GFAP-immunoreactivity in the GCL and ILM (A). GFAP immunopositivity of the Muller glial cells were observed through the whole width of the retina with MSG treatment (B). Muller radial fibers appeared less strongly GFAP-positive after Ucn 2 treatment (C). Abbreviations: OLM - outer limiting membrane; ILM - inner limiting membrane. Scale bar: $20 \mu \mathrm{m}$ 
In rat retina, vesicular glutamate transporter 1 (VGLUT1) has been described in the OPL and throughout the IPL, consistently with the expected synaptic localization of the protein (15). In our normal control preparations, VGLUT-1-immunopositive structures were also present in the OPL and IPL, and few VGLUT1-positive cells could be observed in the GCL. VGLUT1 staining in the OPL and IPL of the rat retina shows the terminals of photoreceptors and bipolar cells, respectively (Fig. 3A). MSG-treated retinas showed severe degeneration compared to control retinas. In concert with the histological observation the intermingled inner retinal layers expressed substantially reduced VGLUT1-positivity (Fig. 3B). Ucn 2 treatment led to a nearly normal appearance of VGLUT1-immunoreactivity in retinal structures (Fig. 3C).

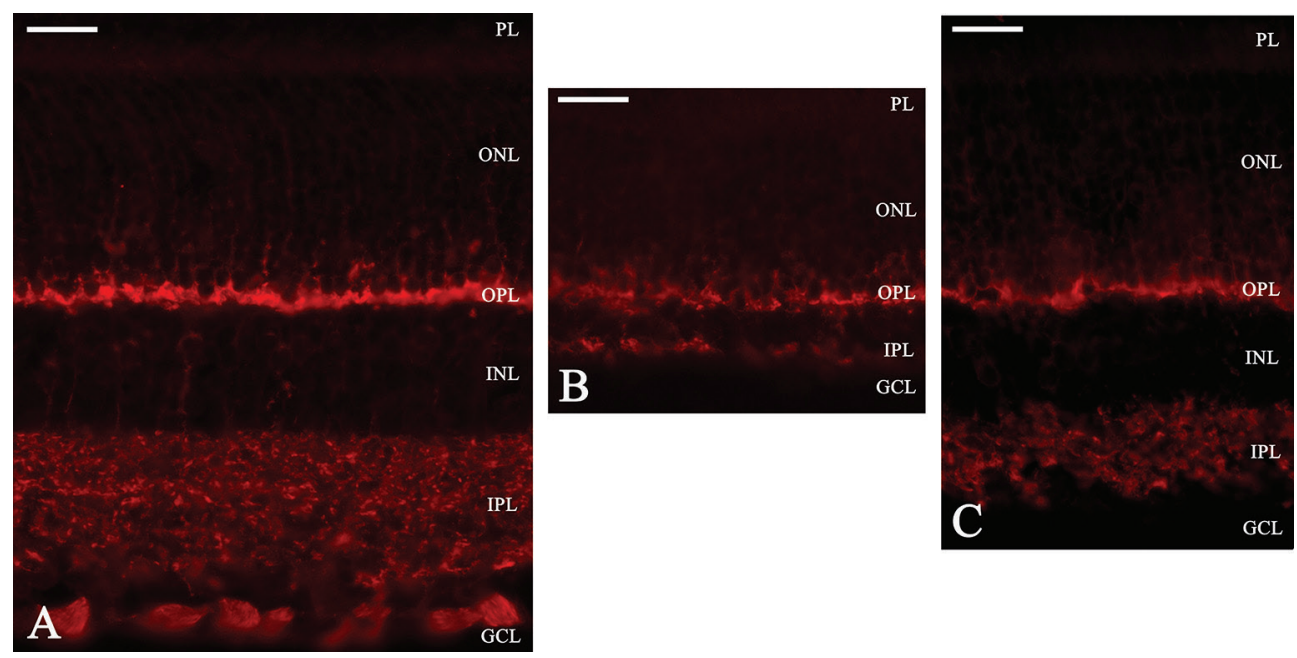

Fig. 3. VGLUT1 staining in control (A), MSG- (B) and MSG+Ucn 2-treated retinas (C). VGLUT1 expression could be observed in OPL, IPL and GCL of the rat retina. After three times MSG treatment, damage to the bipolar cell terminals in the IPL is obvious, Ucn 2 treatment ameliorated the damage of the VGLUT1 expressing structures.

Abbreviations: PL - photoreceptor layer; ONL - outer nuclear layer; OPL - outer plexiform layer; INL - inner nuclear layer; IPL - inner plexiform layer; GCL - ganglion cell layer. Scale bar: $20 \mu \mathrm{m}$

The presence of protein kinase $\mathrm{C} \alpha(\mathrm{PKC} \alpha)$ was detected in the rod bipolar cell population in the rat retina (34). The labeled structures were the cell bodies of the INL and cell processes extending into the IPL, close to the GCL (Fig. 4A). Differences between control and MSGtreated retinas were observed in the arborization and the number of rod bipolar cells (Fig. 4B). Ucn 2 treatment substantially counteracted the MSG-induced changes in PKC $\alpha$ immunolabeling (Fig. 4C). 

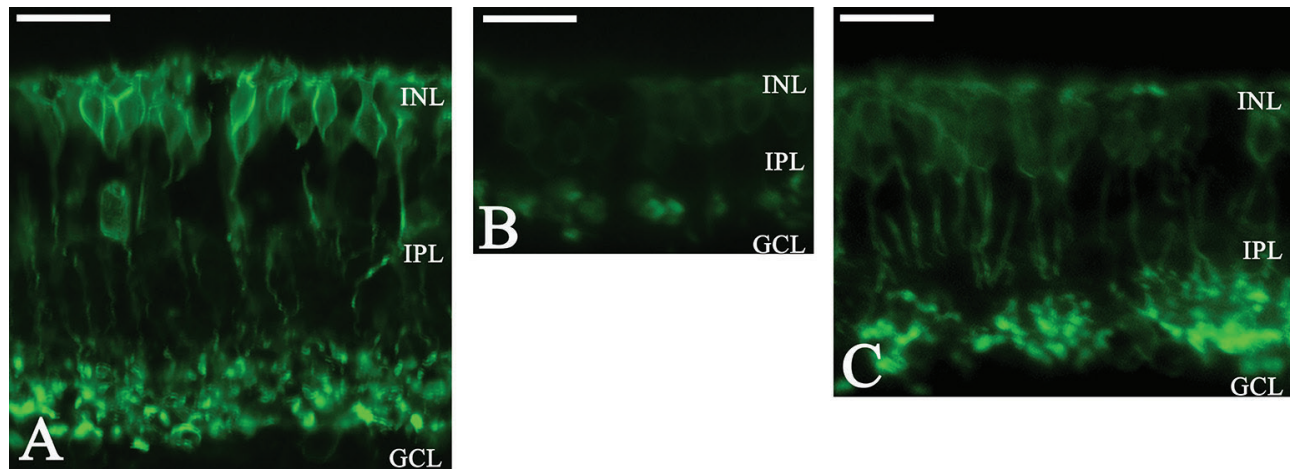

Fig. 4. Rod bipolar cells revealed by PKC $\alpha$ immunostaining. Control (A), MSG- (B) and $\mathrm{MSG}+3 \mathrm{xU}$ en 2-treated retinas (C).

Rod bipolar cells are fewer and less strongly stained in MSG-treated tissues (B) than in control (A). Ucn 2 treatment resulted in not only protection of the retinal layers, but also retained the density of the immunoreactive cells which was similar to that of the control tissue (C).

Abbreviations: INL - inner nuclear layer; IPL - inner plexiform layer; GCL - ganglion cell layer.

Scale bar: $20 \mu \mathrm{m}$

$\mathrm{Ca}^{2+}$-binding proteins such as calbindin, parvalbumin and calretinin are abundant in various layers of the mammalian retina $(16,17)$. Calbindin immunoreactivity was found in the cell bodies and processes of the horizontal cells (Fig. 5A). MSG treatment generated only a slight alteration in the pattern of immunoreactivity (Fig. 5B). After Ucn 2 treatment immunoreactivity was similar to the control level (Fig. 5C). Parvalbumin immunoreactivity was identified in the population of AII glycinergic amacrine cells and in a few ganglion cells in control retinas (Fig. 5D). Almost no parvalbumin-positive cells could be detected in MSGtreated retinas (Fig. 5E). In Ucn 2-treated retinas, the structure was similar to the controls, but the IPL was thinner than in the untreated tissue (Fig. 5F). Calretinin-positive cells could be found in the subpopulations of inner retinal cell classes, especially in ganglion and amacrine cells and their processes in the IPL (Fig. 5G). MSG caused the fusion of the inner retinal layers leading to the decreased labeled cell number (Fig. 5H). In most cases, Ucn 2 treatment not only resulted in a protection of the retinal layers but it also led to a retained density of the immunoreactive cells (Fig. 5I).
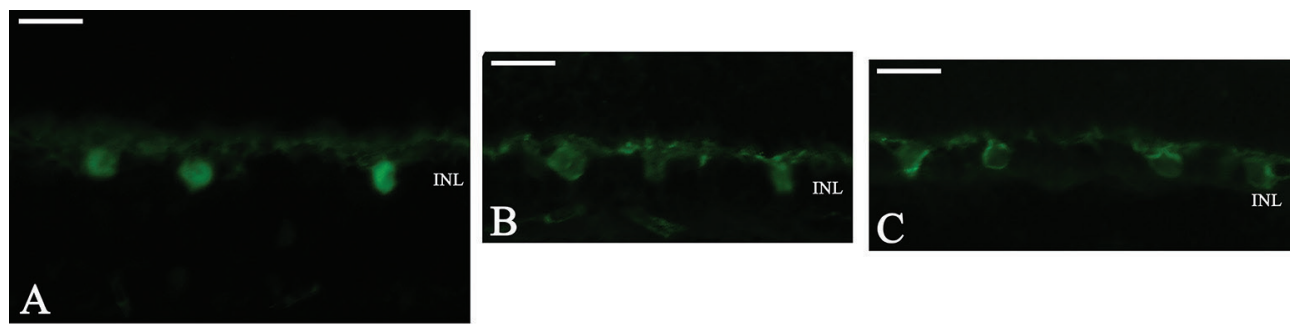

A 

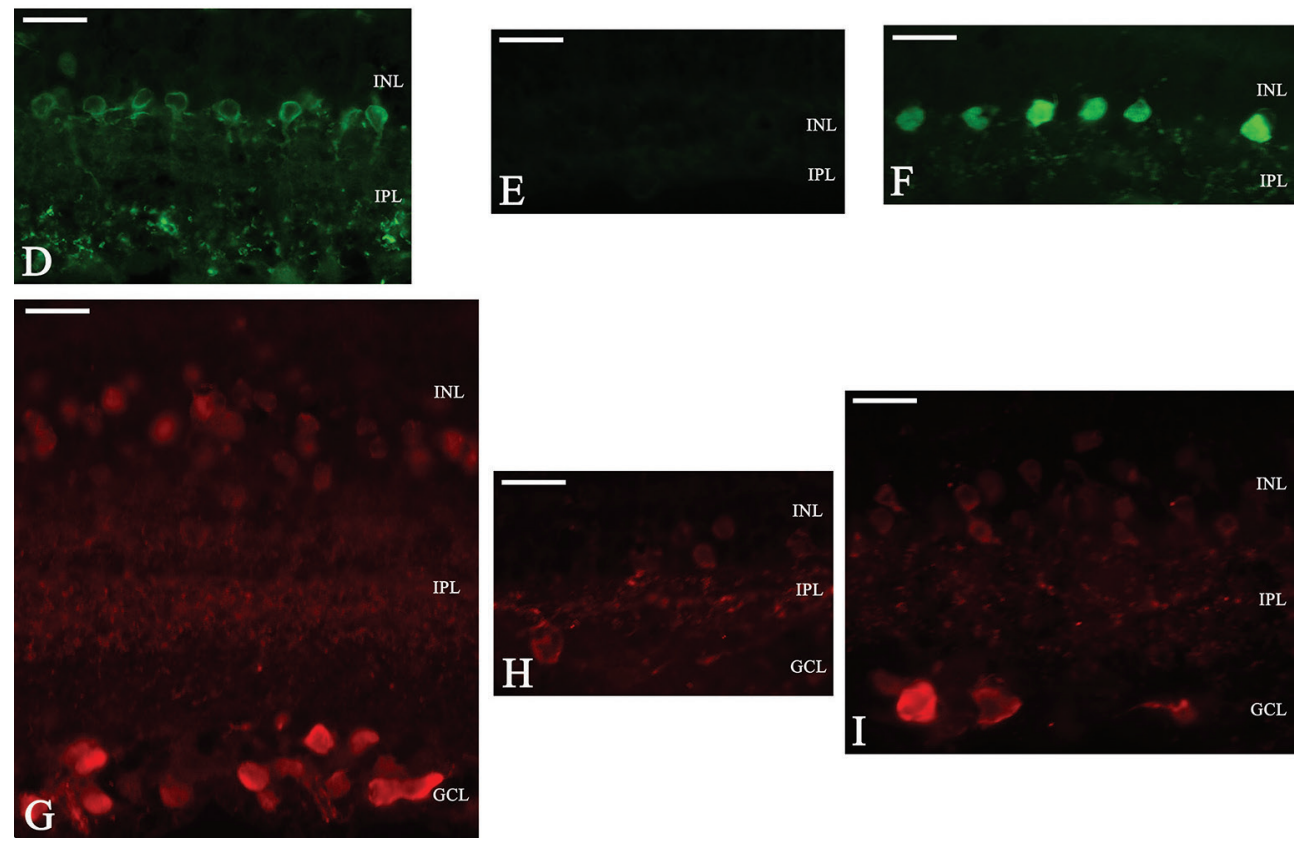

Fig. 5. $\mathrm{Ca}^{2+}$-binding proteins (calbindin, parvalbumin and calretinin) expression in control $(\mathrm{A}, \mathrm{D}, \mathrm{G}), \mathrm{MSG}(\mathrm{B}, \mathrm{E}, \mathrm{H})$ and $\mathrm{MSG}+\mathrm{Ucn}$ 2-treated $(\mathrm{C}, \mathrm{F}, \mathrm{I})$ groups.

In control, the calbindin is present in cell bodies and processes of the horizontal cells (A). No difference, only minimal decrease in intensity of calbindin staining could be observed after MSG application (B).

After MSG+Ucn 2 treatment calbindin expressing structures were retained (C).

Parvalbumin immunohistochemistry labeled numerous AII amacrine cells in the control retina (D). Immunoreactivity in the MSG-treated retinas was apparently reduced (E). MSG+Ucn 2-treated retina structure was almost similar, but the immunoreactivity seemed weaker than that of the control tissue $(\mathrm{F})$.

Calretinin is normally present in amacrine and ganglion cells and their projections in the INL, IPL and GCL (G). MSG treatment caused the fusion of the inner retinal layers (INL, IPL, GCL) so immunoreactivity seemed weaker, and the number of labeled retinal cells decreased $(\mathrm{H})$. Ucn 2 treatment counteracted the MSG-induced changes in calretinin-immunolabeling (I).

Abbreviations: INL - inner nuclear layer; IPL - inner plexiform layer; GCL - ganglion cell layer. Scale bar: $20 \mu \mathrm{m}$

\section{Discussion}

The members of CRF peptide family and their receptors are found throughout the central nervous system, including the retina (21). In the present study we proved that Ucn 2 treatment was protective in MSG-induced retinal degeneration, retaining structural integrity of the tissue and the neurochemical characteristics of several nerve cell types.

Urocortins are the ancient paralogs of CRF-Rs (14). In the retina, CRF-like immunoreactivity has been described in horizontal, amacrine and ganglion cells and their processes (35-39). It has been formerly reported that Ucn 1 confers its neuroprotective activity through CRF1-Rs via cAMP-dependent pathways (13). The receptor subtype underlying the presently shown retinoprotective action of Ucn 2 remains to be determined. In the retina the two CRF receptor subtypes are present at both mRNA and protein levels (10, 40). Based on the present findings, the relevance of endogenous $C R F / U c n s$ to retinal function should be further explored. 
Retinal MSG excitotoxicity leads to degeneration of cells in all retinal layers through a complex mechanism involving apoptosis $(23,24)$. The inner retinal cells bear functional ionotropic glutamate receptors, the potential targets of MSG toxicity. A variety of pharmacological approaches has been shown to be protective against MSG-induced damage and may be relevant to the protective action of Ucn 2 observed here. The effectiveness of these protective agents and altered environments in different retinal degeneration models can be compared in the light of the morphometric measurements performed in our previous studies. In the case of whole retina thickness and retinal layers, the order of effectiveness is: enriched environment $>$ diazoxide $>$ PACAP1-38 = PACAP1-27 $>$ Ucn 2. Considering the cell number of ganglion cell layer the rank order is different: enriched environment $=$ diazoxide $=$ PACAP1-38 $=$ PACAP1-27 > Ucn 2 (1-7, 29, 30). More investigations are needed to clear the receptorial and the effector pathway regulation underlying the effects of Ucn 2 exerted in the mammalian retina. Data suggest that Ucn 2 may have protective effects through decreasing metabolic stress to the retina, thus reducing cell loss. Whether these retinoprotective mechanisms involve inhibition of apoptosis, needs to be clarified in future experiments.

\section{Acknowledgements}

Supported by OTKA 100144, 104984; SROP 4.1.2.B-10/2/KONV-20/0-0002, SROP-4.2.2/B-10/1-2010-0029, SROP-4.2.2.A-11/1/KONV-2012-0024; Momentum-Program of the Hungarian Academy of Sciences, Bolyai Scholarship, Akira Arimura Foundation, Richter Gedeon Centenary Foundation and AOK/KA Research Grant of the University of Pécs. The Salk Institute for Biological Studies, La Jolla, CA, USA, and NIH grant DK26741 and to Dr. Eric P. Zorrilla and Dr. Jean E. Rivier for generously providing Ucn 2.

\section{REFERENCES}

1. Atlasz T, Babai N, Reglodi D, Kiss P, Tamas A, Bari F, Domoki F, Gabriel R: Diazoxide is protective in the rat retina against ischemic injury induced by bilateral carotid occlusion and glutamate-induced degeneration. Neurotox. Res. 12, 105-111 (2007)

2. Atlasz T, Szabadfi K, Kiss P, Babai N, Koszegi Z, Tamas A, Reglodi D, Gabriel R: PACAP-mediated neuroprotection of neurochemically identified cell types in MSG-induced retinal degeneration. J. Mol. Neurosci. 36, 97-104 (2008a)

3. Atlasz T: Analysis of the effects of different neuroprotective compounds in retinal degeneration models in rats. $\mathrm{PhD}$ thesis. University of Pécs (2008b)

4. Atlasz T, Szabadfi K, Reglodi D, Kiss P, Tamas A, Toth G, Molnar A, Szabo K, Gabriel R: Effects of pituitary adenylate cyclase activating polypeptide and its fragments on retinal degeneration induced by neonatal monosodium glutamate treatment. Ann. N.Y. Acad. Sci. 1163, 348-352 (2009)

5. Atlasz T, Szabadfi K, Kiss P, Racz B, Gallyas F, Tamas A, Gaal V, Marton Z, Gabriel R, Reglodi D: Pituitary adenylate cyclase activating polypeptide in the retina: focus on the retinoprotective effects. Ann. N.Y. Acad. Sci. 1200, 128-139, Review (2010)

6. Babai N, Atlasz T, Tamas A, Reglodi D, Toth G, Kiss P, Gabriel R: Degree of damage compensation by various PACAP treatments in monosodium glutamate-induced retinal degeneration. Neurotox. Res. 8, 227-233 (2005)

7. Babai N, Atlasz T, Tamas A, Reglodi D, Toth G, Kiss P, Gabriel R: Search for the optimal monosodium glutamate treatment schedule to study the neuroprotective effects of PACAP in the retina. Ann. N.Y. Acad. Sci. 1070, 149-155 (2006)

8. Chambille I, Serviere J: Neurotoxic effects of neonatal injections of monosodium L-glutamate (L-MSG) on the retinal ganglion cell layer of the golden hamster: anatomical and functional consequences on the circadian system. J. Comp. Neurol. 338, 67-82 (1993) 
9. Choi JS, Pham TT, Jang YJ, Bui BC, Lee BH, Joo KM, Cha CI, Lee KH: Corticotropin-releasing factor (CRF) and urocortin promote the survival of cultured cerebellar GABAergic neurons through the type $1 \mathrm{CRF}$ receptor. J. Kor. Med. Sci. 21, 518-526 (2006)

10. Dautzenberg FM, Huber G, Higelin J, Py-Lang G, Kilpatrick GJ: Evidence for the abundant expression of arginine 185 containing human CRF2 receptors and the role of position 185 for receptor-ligand selectivity. Neuropharmacology 39, 1368-1376 (2000)

11. Dautzenberg FM, Hauger RL: The CRF peptide family and their receptors: yet more partners discovered. Trends Pharmacol. Sci. 23, 71-77 (2002)

12. Eng LF, Smith ME, De Vellis J, Skoff RP: Recent studies on the glial fibrillary acidic protein. Ann. N.Y. Acad. Sci. 455, 525-537 (1985)

13. Facci L, Stevens DL, Pangallo M, Franceschini D, Skaper SD, Strijbos PJLM: Corticotropin-releasing factor $(\mathrm{CRF})$ and related peptides confer neuroprotection via type 1 CRF receptors. Neuropharmacology 45, 623-636 (2003)

14. Fekete EM, Zorrilla EP: Physiology, pharmacology and therapeutic relevance of urocortins in mammals: Ancient CRF paralogs. Frontiens in Neuroendocrinol. 28, 1-27 (2007)

15. Gong J, Jellali A, Mutterer J, Sahel JA, Rendon A, Picaud S: Distribution of vesicular glutamate transporters in rat and human retina. Brain Res. 1082, 73-85 (2006)

16. Hamano K, Kiyama H, Emson PC, Manabe R, Nakauchi M, Tohyama M: Localization of two calcium binding proteins, calbindin $(28 \mathrm{kD})$ and parvalbumin $(12 \mathrm{kD})$, in the vertebrate retina. J. Comp. Neurol. 302, 417-424 (1990)

17. Hwang IK, Yoo KY, Kim DS, Jung JY, Shin MC, Seo K, Kim KS, Kang TC, Won MH: Comparative study on calretinin immunoreactivity in gerbil and rat retina. Anat. Histol. Embryol. 34, 129-131 (2005)

18. Lopez-Perez SJ, Ureña-Guerrero ME, Morales-Villagran A: Monosodium glutamate neonatal treatment as a seizure and excitotoxic model. Brain Res. 1317, 246-256 (2010)

19. Osborne NN, Casson RJ, Wood JP, Chidlow G, Graham M, Melena J: Retinal ischemia: mechanisms of damage and potential therapeutic strategies. Prog. Retin. Eye Res. 23, 91-147, Review (2004)

20. Osborne M, Weber K: Cell-type specific markers in differentiation and pathology. Cell 31, 303 (1982)

21. Pan W, Kastin AJ: Urocortin and the brain. Prog. Neurobiol. 84, 148-156 (2008)

22. Pedersen WA, Wan R, Zhang P, Mattson MP: Urocortin, but not urocortin II, protects cultured hippocampal neurons from oxidative and excitotoxic cell death via corticotropin-releasing hormone receptor type I. J. Neurosci. 22, 404-412 (2002)

23. Racz B, Gallyas F Jr, Kiss P, Toth G, Hegyi O, Gasz B, Borsiczky B, Ferencz A, Roth E, Tamas A, Lengvari I, Lubics A, Reglodi D: The neuroprotective effects of PACAP in monosodium glutamate-induced retinal lesion involve inhibition of proapoptotic signaling pathways. Regul. Pept. 137, 20-26 (2006a)

24. Racz B, Tamas A, Kiss P, Toth G, Gasz B, Borsiczky B, Ferencz A, Gallyas F Jr, Roth E, Reglodi D: Involvement of ERK and CREB signaling pathways in the protective effect of PACAP in monosodium glutamate-induced retinal lesion. Ann. N.Y. Acad. Sci. 1070, 507-511 (2006b)

25. Romano C, Price MT, Olney JW: Delayed excitotoxic neurodegeneration induced by excitatory amino acid agonists in isolated retina. J. Neurochem. 65, 59-67 (1995)

26. Schmidt KG, Bergert H, Funk RH: Neurodegenerative diseases of the retina and potential for protection and recovery. Curr. Neuropharmacol. 6(2), 164-178 (2008)

27. Skofitsch G, Jacobowitz DM: Corticotropin releasing factor-like immunoreactive neurons in the rat retina. Brain Res. Bull. 12, 539-542 (1984)

28. Sucher NJ, Lipton SA, Dreyer EB: Molecular basis of glutamate toxicity in retinal ganglion cells. Vision Res. 37, 3483-3493 (1997)

29. Sun Q, Ooi VE, Chan SO: N-methyl-D-aspartate-induced excitotoxicity in adult rat retina is antagonized by single systemic injection of MK-801. Exp. Brain Res. 138, 37-45 (2001)

30. Szabadfi K, Atlasz T, Reglodi D, Kiss P, Danyadi B, Fekete EM, Zorrilla EP, Tamas A, Szabo K, Gabriel R: Urocortin 2 protects against retinal degeneration following bilateral common carotid artery occlusion in the rat. Neurosci. Lett. 455, 42-45 (2009a)

31. Szabadfi K, Atlasz T, Horvath G, Kiss P, Hamza L, Farkas J, Tamas A, Lubics A, Gabriel R, Reglodi D: Early postnatal enriched environment decreases retinal degeneration induced by monosodium glutamate treatment in rats. Brain Res. 1259, 107-112 (2009b)

32. Tamas A, Gabriel R, Racz B, Denes V, Kiss P, Lubics A, Lengvari I, Reglodi D: Effects of pituitary adenylate cyclase activating polypeptide in retinal degeneration induced by monosodium-glutamate. Neurosci. Lett. 372 , 110-113 (2004) 
33. Vidal-Sanz M, Lafuente M, Sobrado-Calvo P, Selles-Navarro I, Rodriguez E, Mayor-Torroglosa S, VillegasPerez MP: Death and neuroprotection of retinal ganglion cells after different types of injury. Neurotox. Res. 2, 215-227 (2000)

34. Wassle H, Yamashita M, Greferath U, Grunert U: The rod bipolar cell of the mammalian retina. Vis. Neurosci. 7, 99-112 (1991)

35. Williamson DE, Eldred WD: Synaptic organization of two types of amacrine cells with CRF-like immunoreactivity in the turtle retina. Vis. Neurosci. 6, 257-269 (1991)

36. Williamson DE, Eldred WD: Amacrine and ganglion cells with corticotrophin releasing-factor like immunoreactivity in the turtle retina. J. Comp. Neurol. 280, 424-435 (1989)

37. Zhang DR, Gallagher M, Sladek CD, Yeh HH: Postnatal development of corticotrophin releasing factor-like immunoreactive amacrine cells in the rat retina. Brain Res. Dev. Brain Res. 51, 185-194 (1990)

38. Zhang DR, Yeh HH: Corticotropin releasing factor-like immunoreactivity (CRFLI) in horizontal cells of the developing rat retina. Vis. Neurosci. 6, 383-391 (1991)

39. Zhang DR, Yeh HH: Histogenesis of corticotropin releasing factor-like immunoreactive amacrine cells in the rat retina. Brain Res. Dev. Brain Res. 53, 194-199 (1990)

40. Zmijewski MA, Sharma RK, Slominski AT: Expression of molecular equivalent of hypothalamic-pituitaryadrenal axis in adult retinal pigment epithelium. J. Endocrinol. 193, 157-169 (2007) 